Введение. Парентеральные вирусные гепатиты B, C и D - одна из глобальных проблем мирового здравоохранения.

Цель исследования. Проанализировать влияние вирусных гепатитов в Республике Казахстан на современном этапе.

Материал и методы. В исследовании применены показатели описательной статистики Научно-практического центра "Санитарно-эпидемиологической экспертизы и мониторинга» Комитета по защите прав потребителей Министерства национальной экономики (МНЭ) Республики Казахстан (РК) и Комитета по статистике МНЭ РК.

Результаты. В РК введение в календарь профилактических прививок вакцинации против гепатита В привело к значительному снижению заболеваемости вирусным гепатитом В среди населения младше 18 лет. Однако наблюдается рост заболеваемости дельта гепатитом, к примеру за период с 2012 по 2016 ге. заболеваемость хроническим вирусным гепатитом В с дельта агентом граждан старше 18 лет выросла на 50\% и составила 0,57 случая на 100 тыс. человек.

Выводы. С учетом увеличения доступа к высокоактивным противовирусным агентам в РК представлена парадигма прогнозируемой элиминации гепатита С. Актуальным становится вопрос изучения стеатоза печени в связи с возрастающим глобальным ростом метаболических нарушений, в том числе и в РК.

Ключевые слова: хронический гепатит $B$, гепатит $D$, хронический гепатит $C$, Республика Казахстан, фиброз печени, стеатоз.

\title{
CHRONIC VIRAL HEPATITIS IN THE REPUBLIC OF KAZAKHSTAN AT THE PRESENT STAGE: FACTORS INFLUENCING THE COURSE AND OUTCOMES, THE ROLE OF METABOLIC SYNDROME
}

\author{
A. A. Konysbekova, K. S. Kaliaskarova, F. K. Bekenova \\ Medical University of Astana, Nur-Sultan, Kazakhstan
}

Background. Parenteral viral hepatitis B, C and D are one of the main problems of healthcare worldwide.

Objective - to analyze the effect of viral hepatitis in the Republic of Kazakhstan at the present stage.

Material and methods. The study used indicators of descriptive statistics of the scientific and practical center "Sanitary and Epidemiological Expertise and Monitoring" of the Committee for the Protection of Consumer Rights of the Ministry of National Economy (MNE) of the Republic of Kazakhstan (RK) and of the Committee for Statistics of the MNE of RK.

Results. The introduction of a vaccination against hepatitis $B$ into Vaccination schedule has led to a significant decrease in the incidence of viral hepatitis B among people under 18 years of age in the Republic of Kazakhstan. However, there is an increase in the incidence of delta hepatitis, for example, from 2012 to 2016, the incidence of chronic viral hepatitis B with delta agent in citizens over 18 years old increased by $50 \%$ and amounted to 0.57 cases per 100 thousand people.

Conclusions. Taking into account the increase in access to highly active antiviral agents in the Republic of Kazakhstan, the paradigm of projected elimination of hepatitis $C$ is presented. The study of hepatic steatosis is becoming relevant, due to the increasing rate of metabolic disorders worldwide, including the Republic of Kazakhstan.

Keywords: chronic hepatitis B, hepatitis D, chronic hepatitis C, Republic of Kazakhstan, liver fibrosis, steatosis.

Автор, ответственный за переписку:

Конысбекова Алия Анапьяровна; НАО «Медицинский

Университет Астана», Нур-Султан, Казахстан;

e-mail: alanakon_dok@mail.ru

Для цитирования:

Конысбекова, А. А. Хронические вирусные гепатиты в республике Казахстан на современном этапе: факторы, влияющие на течение и исходы, роль метаболического синдрома / А. А. Конысбекова, К. С. Калиаскарова, Ф. К. Бекенова // Гепатология и гастроэнтерология. 2020. Т. 4, № 1. С. 62-67. https://doi.org/10.25298/2616-5546-2020-4-1-62-67
Corresponding author:

Konysbekova Alia; Medical University of Astana, Nur-Sultan, Kazakhstan;

e-mail: alanakon_dok@mail.ru

For citation:

Konysbekova AA, Kaliaskarova KS, Bekenova FK. Chronic viral hepatitis in the republic of Kazakhstan at the present stage: factors influencing the course and outcomes, the role of metabolic syndrome. Hepatology and Gastroenterology. 2020;4(1):62-67. https://doi.org/10.25298/2616-5546-2020-4-1-62-67 


\section{Введение}

Парентеральные вирусные гепатиты B, C и D - одна из глобальных проблем мирового здравоохранения. Более 350 млн людей во всем мире являются носителями вируса В, из которых 1540\% (75-160 млн) подвержены угрозе развития цирроза печени или гепатоцеллюлярной карциномы [1]. Ситуация с гепатитом C положительно меняется, количество инфицированных вирусом С снижается, в настоящее время страдают порядка 71 млн человек. Заболеваемость HDV-инфекцией снизилась в эндемичных странах в результате эфффективной иммунопрофилактики против HBV и улучшения социально-экономических и гигиенических условий, однако остается актуальной причиной заболеваемости в Азиатско-Тихоокеанском регионе [2, 3]. Гепатит В с дельта агентом - серьезная проблема и в Республике Казахстан. Статистика распространенности HDV до сих пор уточняется. HDV-инфекция повышает риск развития гепатоцеллюлярной карциномы (ГЦК) в три раза и смертности - в два раза - у пациентов с HBsAg-позитивным циррозом печени. Согласно исследованию, постоянная репликация HDV приводит к циррозу и ГЦК в годовом исчислении 4 и 2,8\%, соответственно, и является предиктором печёночной смерти $[4,5]$.

Цель исследования - представить эпидемиологические и клинико-терапевтические аспекты, связанные с распространением хронических гепатитов B, C и D в Республике Казахстан.

\section{Материал и методы}

В исследовании применены показатели описательной статистики НПЦ «Санитарно-эпидемиологической экспертизы и мониторинга» КЗПП МНЭ РК и КС МНЭ РК.

\section{Результаты и обсуждение}

Эпидемиология. Республика Казахстан относится к странам с высокой эндемичностью (более 8\%) по распространению вируса гепатита В (ВГВ) [5]. Согласно экспертным оценкам, скрининговые исследования в группах риска в 2014 г. выявили наличие HBsAg у 2,3\% населения. Среди беременных и доноров крови распространенность ВГВ 1,3\% в 2013 г. и 1,2\% в 2014 г., соответственно. К значительным успехам в борьбе с ВГВ привело введение в календарь профилактических прививок вакцинации против гепатита В. В результате заболеваемость снизилась почти в 40 раз: с 29,3 в 1997 г. до 0,8 на 100000 населения в 2014 г. В целом за последние 20 лет уровень заболеваемости снижен в 23,7 раза, среди детей - в 52 раза [6].

Несмотря на проводимые эфффективные меры, возрастает количество выявляемых микст-гепатитов, в число которых входит гепатит
B c D-агентом [7]. Наши исследования пятилетнего среза показали, что заболеваемость хроническим гепатитом В (ХГВ) в Казахстане в целом имеет тенденцию к спаду [7]. Так, если количество заболеваний ХГВ в 2012 г. было на уровне 35,4 случая на 100 тыс. населения, то в 2016 г. показатель уменьшился на 5,8 случая $(\downarrow 16,4 \%)$ и составил 29,6 на 100 тыс. человек. В течение рассматриваемого периода существенное снижение случаев ХГВ зарегистрировано в 2015 г. (27,9 на 100 тыс. человек), которое далее сопровождалось незначительным ростом заболеваемости в 2016 г. - на $6 \%$, или 1,7 случая на 100 тыс. человек.

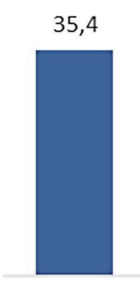

2012

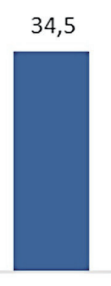

2013

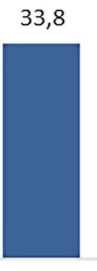

2014

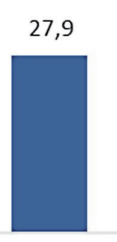

2015

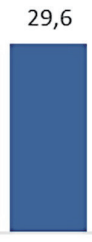

2016
Рисунок1.-ЗаболеваемостьХГВ(на100тыс.)с2012по2016г2. Figure 1. - The incidence of chronic hepatitis $B$ (per 100 thousand) from 2012 to 2016

Примечательным является то, что заболеваемость ХГВ среди детей и подростков существенно сократилась. Так, в 2012- 2016 гг. дети до 14 лет стали болеть ХГВ 3,7 раза меньше (с 6,3 до 1,7 случаев), а подростки 15-17 лет - в 4,8 раза реже (с 22,4 до 4,7 случаев на 100 тыс. человек).

По итогам 2016 г. заболеваемость ХГВ с D-агентом составила 0,39 случая на 100 тыс. человек.

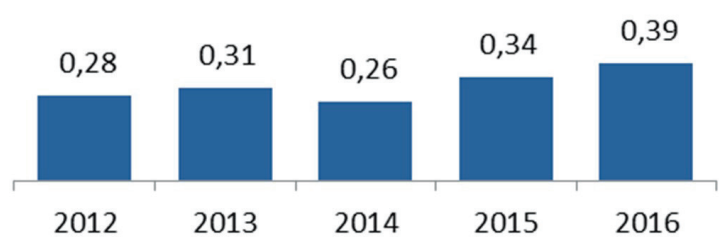

Рисунок 2. - Заболеваемость ХВГ с D-агентом, случаев на 100 тыс. человек

Figure 2. - The incidence of $\mathrm{CVH}$ with D-agent, cases per 100 thousand people

В целом сравнительно с общим ХГВ с D-агентом цифра небольшая, однако статистика показывает рост заболеваемости. Так, за последние 5 лет заболеваемость ХГВ с D-агентом выросла на $40 \%$ - с 0,28 до 0,39 случая на 100 тыс. человек. Причем в 2015 и 2016 гг. темп роста был высоким и составил 31 и 13\%, соответственно.

Как и при ХГВ, количество заболеваний ХГВ c D-агентом в большей степени распространено среди населения старше 18 лет. Примечательно то, что ХГВ с D-агентом практически не встречается среди детей, а заболеваемость среди 
подростков 15-17 лет стремительно снизилась с 0,38 случая, впервые выявленных на 100 тыс. населения в 2012 г. до нуля в 2016 г.

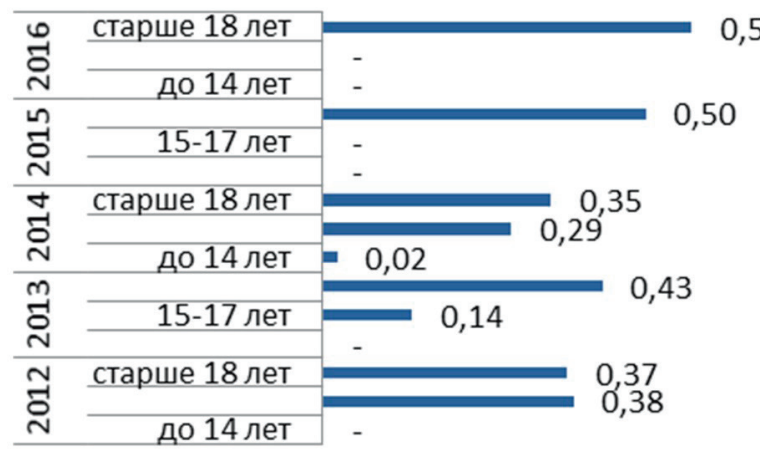

Рисунок 3. - Заболеваемость ХГВ с D-агентом в основных возрастных группах, случаев на 100 тыс. человек Figure 3. - The incidence of chronic hepatitis $B$ with $D$-agent in the main age groups, cases per 100 thousand people

Согласно данным последних эпидемиологических исследований, распространенность инфрекции вирусом гепатита С (ВГС), оцениваемая по частоте обнаружения anti-HCV, может варьировать в зависимости от региона, но в целом по стране составляет 3,1\% [8], что в 2013 г. составляло 483 тыс. человек в стране. Среди них виремия встречается почти у $75 \%$ человек, или у 2,4\% инфицированных и соответствует 362 тыс. пациентов с ХГС.

Распространенность ХГС оценивалась на основании применения к общей популяции данных о распространенности в Алмате 3,0\% и в Южно-Казахстанской области 4,6\%, что в среднем составило 3,9\% среди населения в возрасте 1869 лет [6].

Таблица 1. - Распространенность ХГС и частота виремии HCV среди населения Республики Казахстан в 2013 г. (абс/\%)

Table 1. - The prevalence of chronic hepatitis $C$ and the frequency of HCV viremia among the population of the Republic of Kazakhstan in 2013 (abs. /\%)

\begin{tabular}{|l|c|c|}
\hline \multicolumn{1}{|c|}{ Показатель } & Частота (\%) & Всего случаев \\
\hline Распространенность HCV & $3,1(2,7-4,6)$ & 483,280 \\
\hline Виремия HCV & $2,4(1,9-3,4)$ & 362,460 \\
\hline
\end{tabular}

На рисунке 4 представлен показатель распространенности ВГС-инфекции в Казахстане по полу и во всех возрастных группах населения Республики Казахстан.

На рисунке 5 представлен показатель общего числа инфицированных HCV по возрасту в 2016 г. среди населения Республики Казахстан.

Метаболический синдром (МС). Изучение факторов, способствующих усилению трансформации вирусных гепатитов в цирроз и гепатоцеллюлярную карциному, - важное направление в

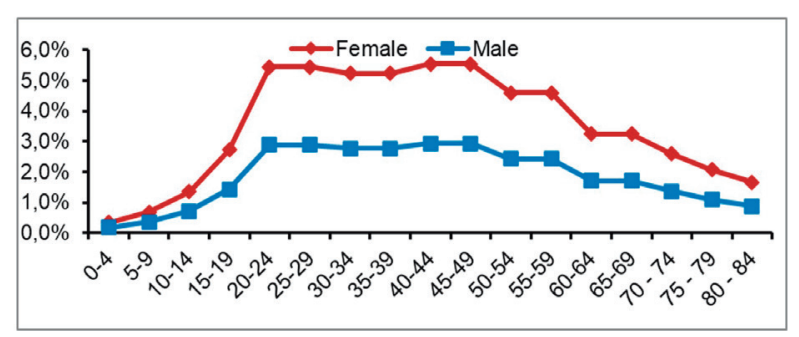

Рисунок 4. - Распространенность ВГС инфекции в Казахстане по полу и возрасту

Figure 4. - The prevalence of HCV infection in Kazakhstan by gender and age

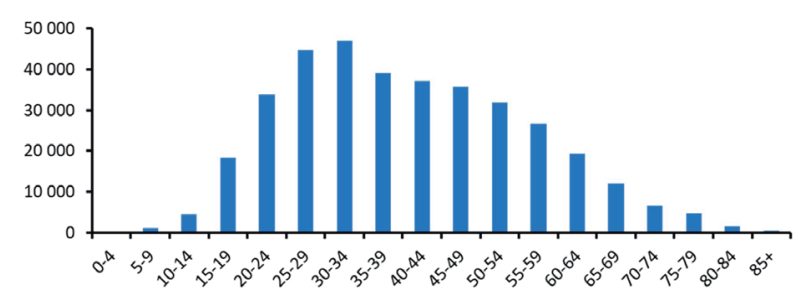

Рисунок 5. - Общее число инфицированных HCV по возраcmy в 2016 z.

Figure 5. - Total number of HCV infected by age in 2016

гепатологии. Так, известно влияние употребления алкоголя, высокой вирусной нагрузки, возраста, мужского пола, позитивного на $\mathrm{HBeAg}$ теста, коинфекции с вирусами гепатита D и C, вирусом иммунодефицита человека (ВИЧ) [9-11]. В числе наиболее актуальных изучаемых факторов влияния в настоящее время - $\mathrm{MC}$, нарушение толерантности к глюкозе, дефицит витамина D. Инсулинорезистентность ассоциируется с усилением воспалительно-некротических изменений печени и формированием стеатоза [12]. Влиянию стеатоза на течение ХГВ посвящено относительно немного исследований. Распространенность стеатоза печени при ХГВ составляет, по данным разных авторов, от 27 до 51\%, и до конца не определена его роль в прогрессировании фииброза и цирроза печени при этом заболевании. В то же время ассоциация HDV гепатита со стеатозом практически не изучена.

Неалкогольную жировую болезнь печени (НАЖБП) расценивают как печеночную манифестацию МС. В работах по изучению роли витамина D у пациентов с ожирением установлено, что с дефицитом витамина $\mathrm{D}(<10 \mathrm{ng} / \mathrm{mL})$ ассоциирован более высокий риск развития инсулинорезистентности, МС, артериальной гипертензии и сахарного диабета, причем независимо от наличия ожирения [13]. К биологическим функциям витамина D относят торможение клеточной пролиферации и ангиогенеза, ингибирование продукции ренина, стимуляцию продукции инсулина и кателицидинов. Получены также доказательства того, что низкий уровень витамина D может рассматриваться как независимый предиктор ожирения. В свою очередь ожирение может способствовать снижению уровня циркулирующего 
в крови витамина D за счет повышенного его захвата жировой тканью. Сообщается, что витамин D - важный компонент иммунного модулятора HCV-инфекции и метаболического заболевания печени. У пациентов с ХГС выявлена тенденция более быстрого прогрессирования фриброза на фоне дефицита витамина D [14].

В Республике Казахстан около 90\% населения имеют дефицит витамина D, однако проблема до сих пор остается малоизученной. Имеются единичные исследования по распространенности. Так, результаты одного из исследований, проведенного в г. Алматы, показали, что среди 1387 подростков в возрасте от 10 до 15 лет дефрицит витамина D выявлен более чем у 70\% детей, среди которых выраженный дефицит диагностирован у $31,5 \%$ обследуемых [15]. В отношении HBV-инфицированных пациентов связь между уровнем витамина $\mathrm{D}$, вирусной нагрузкой HBV и дисфункцией печени остается в значительной степени неясной. Все это определяет необходимость исследования роли витамина D в формировании инсулинорезистентности, исходах противовирусной терапии и прогрессировании фриброза у пациентов с вирусными гепатитами в Казахстане.

В Республике Казахстан диагностические возможности для пациентов с заболеваниями печени устойчиво улучшаются. Внедрены методы определения количественной вирусной нагрузки HDV, измерения уровня витамина D, во всех регионах имеется доступ к неинвазивной оценке степени фиброза. Среди визуализационных методов исследования используются компьютерная томография и магнитно-резонансная томография, протонная МР-спектроскопия, позволяющая неинвазивно оценить количественное содержание триглицеридов в печени [10, 16, 17].

Согласно последним практическим рекомендациям Европейской ассоциации по изучению заболеваний печени, транзиентная эластометрия может считаться стандартом неинвазивного теста для измерения эластичности печени (уровень доказательности - А1), имеет высокую достоверность при вирусных гепатитах
(A1), чуть менее достоверна при НАЖБП и других хронических заболеваниях печени (A1), обладает большей чувствительностью при обнаружении цирроза, чем при выявлении «продвинутых» стадий фииброза (A1). CAP (controlled attenuation parameter) - это управляемый параметр ослабления, используемый для количественной оценки интенсивности жировой инфильтрации печени (стеатоза), позволяет количественно рассчитать снижение амплитуды ультразвуковых сигналов в печени. Внедрение датчика XL+Probe позволяет исследовать жесткость печени у пациентов с ожирением и толщиной подкожной клетчатки до 3,5 см, тем самым снизить частоту неудач у

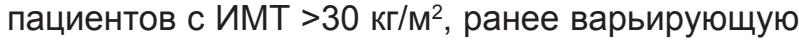
от 3 до 16\% [18]. В то же время диагностическая точность и значимость при комбинированном поражении печени (вирусный гепатит на фоне жирового гепатоза) недостаточна ясна и требует дальнейших исследований.

По данным скринингового фрибросканирования региональных гепатологических центров в 2016 г. установлено, что фиброз на поздних стадиях выявляется в группе пациентов с ХГВ c D-агентом. Распределение пациентов, страдающих от ХВГ с D-агентом, по степени фриброза печени показало, что в основном пациенты диагностируются на этапе продвинутого фииброза F3-F4. Практически во всех макрорегионах доля пациентов в стадии F3-F4 фиброза печени составляет более половины всех наблюдаемых (рис. 6).

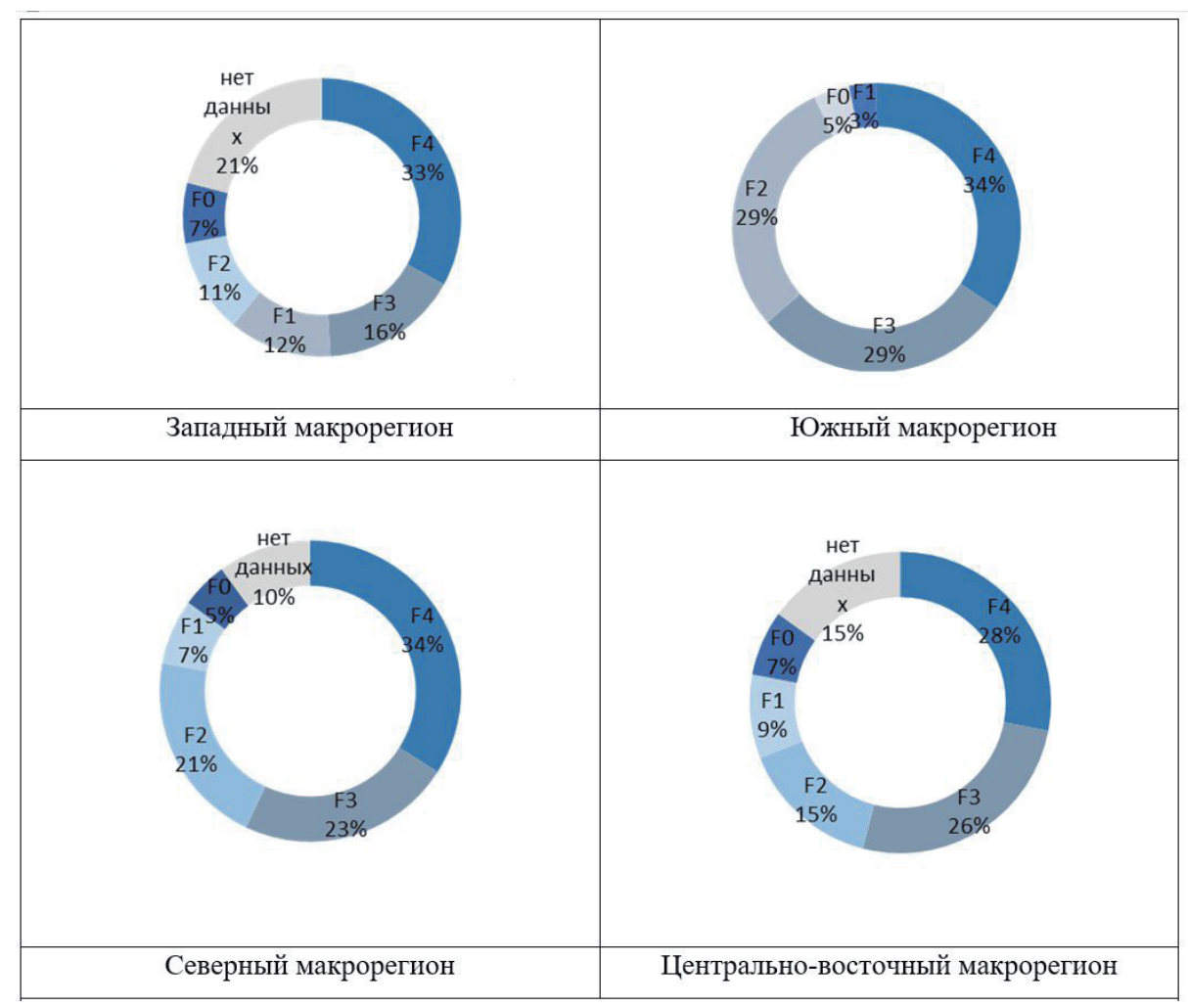

Рисунок 6. - частота выявления фиброза в разных регионах Республики Казахстан Figure 6. - the frequency of detection of fibrosis in different regions of the Republic of Kazakhstan 
Лечение вирусных гепатитов. Цель терапии ХГВ - улучшение прогноза у пациента через устойчивое ингибирование вирусной репликации. Однако имеет место неопределенность и потенциально неограниченная продолжительность курса лечения аналогами нуклеозидов. Во время лечения возникают также вопросы устойчивости и безопасности, финансовые затраты и приверженность пациента. Ингибирование ДНК считается «удовлетворительной конечной точкой», отмена препарата все еще приводит к высоким показателям рецидивов. Клиренс $\mathrm{HBsAg}$ является «идеальной конечной точкой» для решения вопроса о прекращении лечения и влияния на прогноз. В последнее время применение "Оптимизированной стратегии противовирусного лечения" позволило повысить уровень клиренса HBsAg и сделать возможной «идеальную конечную точку».

ВОЗ полагает, что элиминация ВГС возможна и реально достижима, однако доступ к лечению HBV и HCV все еще недостаточный. В текущее время вакцины против HCV не существует, однако ХГС можно излечивать относительно быстро, благодаря использованию высокоэффективных противовирусных препаратов прямого действия. В глобальном докладе ВОЗ о гепатите 2017 г. продемонстрировано, что ряд стран предпринимают успешные шаги для борьбы с гепатитами. В Египте увеличение продукции генерических противовирусных препаратов привело к снижению цены на трехмесячный курс лечения гепатита С (с 900 долларов США в 2015 г. до менее чем 200 долларов США - в 2016 г.). В Пакистане курс лечения стоит в настоящее время около 100 долларов США. В Монголии средства для лечения HBV и HCV включены в Национальную систему медицинского страхования.

С 2018 г. основой лечения ХГС в Республике Казахстан стала комбинированная противовирусная терапия с применением лекарственных средств софосбувир/даклатасвир. В 2018 г. через Международную организацию ЮНИСЕФ был закуплен тенофовир для обеспечения в рамках гарантированного объема бесплатной медицинской помощи пациентам с ХГВ. С 2019 г. Казахстан включен в добровольную лицензию на инновационные препараты от ХГС, что позволяет казахстанским пациентам получать более широкий доступ к лечению. Подписание меморандума и планируемый объем закупа позволит прибли-
Таблица 2. - Состояние и перспективы исходов ХГС на период до 2030 г.

Table 2. - Status and prospects of outcomes of $\mathrm{CHC}$ for the period until 2030

\begin{tabular}{|c|c|c|}
\hline Анализируемые параметры & 2016 & 2030 \\
\hline Ежегодно диагностируется, n & \multicolumn{2}{|c|}{4000} \\
\hline $\begin{array}{l}\text { CВO } \\
\text { ГТ } 1 \\
\text { ГТ } 2 \\
\text { ГТ } 3 \\
\text { ГТ } 4\end{array}$ & & \\
\hline Ежегодно получают лечение & \multicolumn{2}{|c|}{$1750(\geq F 3)$} \\
\hline Всего диагностировано & 58,120 & 72,090 \\
\hline ХГС & 365,050 & 354,460 \\
\hline Компенсированный цирроз & 20,820 & 32,900 \\
\hline Декомпенсированный цирроз & 2140 & 3100 \\
\hline ГЦК & 1180 & 1760 \\
\hline Смерть в исходе болезни печени & 1060 & 1540 \\
\hline
\end{tabular}

зить Казахстан к конечной цели - стать страной с полной элимининацией HCV.

Современная парадигма лечения ХГС в Казахстане: общее число инфицированных может несколько снизиться, но при этом будет нарастать число поздних исходов заболевания (табл. 2).

\section{Выводы}

В Республике Казахстан предпринимаются достаточно эффективные меры по борьбе с вирусными гепатитами. Введение в календарь профилактических прививок вакцинации против ВГС привело к значительному снижению заболеваемости среди населения младше 18 лет. С 2012 по 2016 гг. отмечен рост заболеваемости HDV-гепатитом среди граждан старше 18 лет - на 50\%, что составило 0,57 случая на 100 тыс. человек. B связи с поздней диагностикой HDV-гепатита, высоким риском канцерогенеза, отсутствием эффективного лечения HDV-гепатит становится наиболее опасным вирусным поражением печени и требует активации профилактических мер, включая внедрение экспресс-тестов, усиление эпидемиологического контроля. С увеличением доступа к высокоактивным противовирусным агентам и прогнозируемой элиминацией HCV актуальным становится вопрос изучения стеатоза печени в связи с возрастающим глобальным ростом метаболических нарушений, в том числе и в Республике Казахстан.

\section{References}

1. Vsemirnaja organizacija zdravoohranenija. Gepatit B $\checkmark$ Evropejskom regione VOZ [Hepatitis B in the WHO European Region]. Informacionnyj bjulleten (ijul 2015). [Internet]. Available from: http://www.euro.who.int/ data/ assets/pdf file/0006/283452/fact-sheet-ru-hep-b.pdf?ua=1 (Russian).
2. World Health Organization. Estimations of worldwide prevalence of chronic hepatitis B virus infection: a systematic review of data published between 1965 and 2017. [Internet]. Available from: https://www.who.int/immunization/diseases/ hepatitisB/HBsAg estimates and methods final V3.pdf.

3. Esmembetov KI, Abdurahmanov DT, Odincov $\overline{A V}$, Muhin 
NA. Sovremennye predstavlenija o patogeneze, estestvennom techenii i lechenii gepatita delta (35 let s momenta otkrytija) [Current concepts of pathogenesis, clinical course and treatment of hepatitis delta (35 years since its discovery)]. Klinicheskaja medicina [Clinical Medicine (Russian Journal)]. 2013;91(5):22-26. (Russian).

4. Lopatkina TN, Abdurahmanov DT, Krel PE. Gepatocelljuljarnaja karcinoma i virusy gepatita. Gepatologicheskij forum. 2005;1:20-22. (Russian).

5. World Health Organization. Kazakhstan: WHO statistical profile. [Internet]. Available from: http://www.euro.who.int/ en/countries/kazakhstan.

6. Nersesov AV, Berkinbaev SF, Dzhunusbekova GA, Dzhumabaeva AE, Novickaja MS, Kuanysh N Rasprostranennost virusnyh gepatitov sredi zhitele Juzhno-Kazahstanskoj oblasti [Prevalence of viral hepatitis among residents of South Kazakhstan Region]. Medicina (Almaty) [Medicine (Almaty)]. 2016;9:30-33. (Russian).

7. Razavi-Shearer D, Gamkrelidze I, Nguyen MH, Chen D-S, van Damme P, Abbas Z, Abdulla M, Rached AA, Adda D, Aho I, Akarca U, Hasan F, Lawati F, Naamani K, AlAshgar HI, Alavian SM, Alawadhi S, Albillos A, Al-Busafi SA, Aleman S, Alfaleh FZ, Aljumah AA, Anand AC, Anh NT, Arends JE, ... Konysbekova AA, et al. Global prevalence, treatment, and prevention of hepatitis $B$ virus infection in 2016: a modelling study. Lancet Gastroenterol. Hepatol 2018;3(6):383-403 doi: 10.1016/S2468-1253(18)30056-6.

8. Maaroufi A, Vince A, Himatt SM, Mohamed R, Fung J, Opare-Sem O, Workneh A, Njouom R, Al Ghazzawi I, Abdulla M, Kaliaskarova KS, Owusu-Ofori S, Abdelmageed MK, Adda D, Akin O, Al Baqali A, Al Dweik N, Al Ejji K Al Kaabi S, Al Naamani K, Al Qamish J, Al Sadadi M, A Salman J, Al Badri M, Al-Busafi SA, ... Konysbekova AA, et al. Historical epidemiology of hepatitis $C$ virus in select countries-volume 4. J. Viral Hepat. 2017;24(Suppl 2):8-24. doi: 10.1111/jvh.12762.

9. Kaliaskarova KS. Faktory progressirovanija hronicheskih virusnyh gepatitov $\mathrm{B}, \mathrm{C}$ v korennoj populjacii Kazahstana [master's thesis] Karaganda (Kazahstan); 2010. 24 p. (Russian).
10. Simakova O, editor. Sbornik materialov proekta Ocenka jeffektivnosti realizacii Programmy "Salamatty Қаzaқstan» na pervom jetape (2011-2013)». Almaty: CSPI "Strategija"; 2014. 76 p. (Russian).

11. Pirogova IJu, Pyshkin SA, Efremova EV, Gorfinkel AN, Pogorelova SG, Abramovskaja NV. Diagnosticheskie vozmozhnosti metodov neinvazivnoj ocenki fibroza pri diffuznyh zabolevanijah pecheni. Rossijskij zhurnal gastroenterologii, gepatologii, koloproktologii [Russian Journal of Gastroenterology, Hepatology, Coloproctology]. 2009;19(4):48-54. (Russian).

12. Byrne CD, Targher G. NAFLD: A Multisystem Disease. J. Hepatol. 62(1 Suppl):S47-64. doi: 10.1016/j. jhep.2014.12.012.

13. Zhang Z, Thorne JL, Moore JB. Vitamin D and Nonalcoholic Fatty Liver Disease. Curr. Opin. Clin. Nutr. Metab. Care. 2019;22(6):449-458. doi: 10.1097/ MCO.0000000000000605.

14. Hoan NX, Tong VH, Song LH, Meyer CG, Velavan TP Vitamin $\mathrm{D}$ deficiency and hepatitis viruses-associated liver diseases: a literature review. World J. Gastroenterol. 2018;24(4):445-460. doi: 10.3748/wjg.v24.i4.445.

15. Pushkarev KA, Kausova GK, Berlizeva JuA, Vasilchenko NV, Kajrat G. Deficit vitamina D kak faktor snizhenija rabotosposobnosti u podrostkov [Vitamin D deficiency as a performance decrement factor in adolescents]. Medicina (Almaty) [Medicine (Almaty)]. 2018:2:34-38. (Russian).

16. Yurdaydin C, Idilman R, Bozkaya H, Bozdayi AM. Natural history and treatment of chronic delta hepatitis. J. Viral Hepat. 2010;17(11):749-756. doi: 10.1111/j.13652893.2010.01353.x.

17. Nersesov AV, Isatullaev EA, Palgova LK, Oshakbayev KP, Kaibullayeva ZhA, Raissova AM, Ashimkhanova A. On the issue of HDV-infection in Kazakhstan. Krov. 2011;2:34

18. Didenko VI. Sovremennye dostizhenija v ocenke steatoza pecheni [Recent advances in the assessment of hepatic steatosis]. Gastroenterologija [Gastroenterology]. 2015;3:94-100. (Russian).
Конфликт интересов. Авторы заявляют об отсутствии конфрликта интересов.

Финансирование. Исследование проведено без спонсорской поддержки.

Соответствие принципам этики. Исследование одобрено локальным этическим комитетом.

Сведения об авторах:

Конысбекова Алия Анапьяровна; НАО «Медицинский Университет Астана», Нур-Султан, Казахстан; e-mail: alanakon_dok@mail.ru

Калиаскарова Кульпаш Сагындыковна; д-р мед. наук, НАО «Медицинский Университет Астана», Нур-Султан, Казахстан

Бекенова Фарида Кабешовна, д-р мед. наук, професcop; НАО «Медицинский Университет Астана», Нур-Султан, Казахстан.
Conflict of interest. The authors declare no conflict of interest.

Financing. The study was performed without external funding.

Conformity with the principles of ethics. The study was approved by the local ethics committee.

Information about authors:

Konysbekova Alia; Medical University of Astana, Nur-Sultan, Kazakhstan; e-mail: alanakon_dok@mail.ru

Kaliaskarova Kulpash, PhD, MD (Medicine); Medical University of Astana, Nur-Sultan, Kazakhstan

Bekenova Farida, PhD, MD (Medicine), Professor; Medical University of Astana, Nur-Sultan, Kazakhstan
Поступила: 30.04.2020

Принята к печати: 07.05.2020
Received: 30.04 .2020

Accepted: 07.05.2020 